\title{
Policy Analysis and Institutional Change in Developing Countries: The Brazilian Experience
}

Sandro Cabral is associate professor of operations and strategy at the School of Management of the Federal University of Bahia (UFBA). His research focuses on public-private interactions, organizational boundaries, and efficiency of governments. He was a CAPES-Fulbright Visiting Professor at NYU-Wagner (2013-14), and he has published in journals such as Journal of Public Administration Research and Theory, Long Range Planning, Strategic Entrepreneurship Journal, Public Choice, and Public Money \& Management, among others.

E-mail: scabral@ufba.br
Public Administration Review Vol. 75, Iss. 2, pp. 334-337. (C) 2015 by The American Society for Public Administration. DOI: 10.1111/puar.12348
Jeni Vaitsman, José Mendes Ribeiro, and Lenaura

Lobato, eds., Policy Analysis in Brazil (Bristol:

Policy Press, 2013). 286pp., \$142.50.,

ISBN: 978-1-4473-0684-9.

A fter the transition to democracy in the mid-1980s, Brazil has experienced several institutional changes. These included the introduction of participatory and decentralization mechanisms that emerged from the 1988 Constitution and managerial reforms associated with the pursuit for economic stability, which started in 1994 under the Real Plan. After 2003, Brazil focused on social policies and income distribution programs, and reinforced the role of the internal market to circumvent external turbulences. These changes, and the underlying positive outcomes, have attracted international attention to the largest country in Latin America, as Brazil has become an even more relevant actor onto the global arena. To a large extent, these changes are influenced by policy choices designed by a complex set of actors including political leaders, government bureaucrats, state agencies, NGOs, advocacy groups, multilateral organizations, and business associations.

In Policy Analysis in Brazil, Jeni Vaitsman, José Mendes Ribeiro, and Lenaura Lobato have gathered an impressive amount of evidence about the evolution of policy analysis in Brazil, and more importantly, about how the changes described above influenced policy outcomes in several domains. The editors were able to attract top scholars from reputed universities and research centers in Brazil to collaborate and offer good contributions on the state of the art of policy analysis in the country. As a public management scholar, I found it a pleasure to read this book and learn how scholars are addressing policy analysis issues in Brazil.

In the introduction, the editors highlight the differences between the policy analysis tradition in the United States and Brazil. In the former, policy analysis is oriented to policy problem-solving. In Brazil, according to the editors, policy analysis has a more academic character and has evolved from the interplay among distinct fields such as political science, public administration, economics, sociology, urban planning, and social service. This multifaceted origin may impose some theoretical and empirical constrains and eventually hamper the dialogue with traditional policy analysis authors in other regions of the world. Nevertheless, I believe that the richness of the Brazilian approach to policy analysis may illuminate theory building and offer an enhanced understanding of social phenomena in correlated areas of social science. For instance, in a chapter addressing the collaborative dynamics of the Brazilian HIV policies (Chapter 12 by Fonseca and Bastos), we learn of the relationships developed among several actors involved in this collaborative arena (NGOs, bureaucrats at various governmental levels, multilateral organizations, researchers). This case is likely to shed some light on interorganizational collaboration in the public administration realm (Ansell and Gash 2008) engaging a conversation with scholars interested in topics related to co-production (Bovaird 2007), or even in the reality of service provision to stigmatized groups (Goffman 1963). In the same vein, the interesting taxonomy Andrews offers in Chapter 3 to characterize the methodological diversity of policy analysis in Brazil uses a simple but worthwhile $2 \times 2$ matrix that considers style (economic and sociopolitical) and scope (macro- and micro-analytical). This taxonomy can be useful to better understand policy analysis in other geographical contexts as well.

The book editors present a broad view of policy analysis in Brazil in 20 invited chapters, structured in four sections. Contributions in Part 1 address how policy analysis has been shaped in the country. Part 2 contributors show variations in policymaking at different levels of government from local to federal. Contributions in Part 3 draw attention to the interplay between politics and policy. And Part 4 explores the role of expert communities and knowledge institutions in policy making and analysis. Offering a 
particular entry point into the Brazilian approach to policy analysis, each chapter merits a brief overview of its key ideas, offered below.

Part 1 explores Styles and Methods of Policy Analysis in Brazil, addressing how policy analysis is shaped. Vaitsman, Lobato, and Andrade (Chapter 2) use a longitudinal perspective to analyze the evolution of policy analysis from 1930s to recent days. They describe changes in participation in policymaking (and the nature of participants) throughout the twentieth century, pointing to the growing role of civil society organizations and social movements, even as policy analysis still relies on qualified and capable bureaucrats.

Andrews (Chapter 3) argues that economic lenses have largely influenced policymaking capabilities in Brazil (and in Latin America), as economic development was (and still is) a pending problem in the region. The inherent debts in social development have helped to increase the influence of a sociopolitical style in policy analysis, particularly after the democratization in the 1980s. Consequently, case studies with in-depth contextual information are common in Brazilian policy analysis. The author shows in this chapter that the country is also enhancing micro-economics capabilities to address policy analysis in health and poverty management.

Souza (Chapter 4) illustrates the evolution of bureaucratic capacity building in the Brazilian federal government. She demonstrates that Brazilian investments in capacity building are prominent in social development, urban infrastructure, and mining/ energy and that government is using recently hired and high-skilled professionals to support flagship programs. However, she highlights the cost of these efforts from Brazilian authorities to enhance a professional bureaucracy in the Weberian style: the salaries paid to these servants are above those paid in OECD countries. Future budgetary pressures signal the need for caution and must be taken into account.

\section{Part 2, Policy Analysis by Governments and the}

Legislature, explores different layers of the production of analysis and policymaking at the local, state, and federal levels. The wide range of topics discussed in these chapters offer readers an enhanced vision of the diversity and scope of policy analysis in Brazil.

Ribeiro and Inglez-Dias (Chapter 5) underscore the evolution of planning and budgeting and describe the mechanisms that the Ministry of Planning, Budget, and Management (MPOG) uses to disseminate policy recommendations to other federal government sectors. Paes-Souza and Hellman (Chapter 6) set their sights on the monitoring and evaluation programs at the federal level. Evaluation functions have been institutionalized in Brazil especially after the managerial reforms of the 1990s. The emergence of leading programs in the 2000s (i.e., conditional cash transfer, expansion of higher education, housing, and so on) expanded the role of evaluation to other bodies of the executive branch, complementing the Federal Court of Audit (TCU).

Velasco and Pinheiro (Chapter 7) analyze privatization and policy decision-making from 1985 to 2002. They emphasize the leading role of the federal development bank (BNDES) on the design and the implementation of critical programs. BNDES supported privatizations in Brazil in two distinct ways: technically and financially, and the authors are meticulous in showing the underlying dimensions that shaped the decisionmaking and its rationale.

In Chapter 8, Filgueiras and Rocha focus on policy analysis at the state level, with special attention to agencies producing policy-related information. It is interesting to note, as the authors do, that the federal government stimulated the development of bureaucratic capabilities at the state level to support the implementation of federal policies. These enhanced capabilities were then useful in subsequent policyoriented projects operated independently by the central government. Likewise, some state-level policy agencies are particularly relevant in addressing policy decision-making and supporting the development of local government's plans.

The local level is the focus of Farah in Chapter 9. She looks at urban problems in metropolitan areas and focuses on how housing programs progressed. Her description of the main actors involved can be useful to researchers interested in fine-grained details about housing programs and their outcomes at the local level.

Finally, Santos (Chapter 10) analyzes the dynamics of decision-making in the Brazilian Parliament. He opens a dialogue between policy analysis and positive political theory (Pereira and Mueller 2004) when he displays the importance of technical committees in setting the decision-making agenda. The author shows that information asymmetries and divergent preferences between members of the legislature and executive powers, as well as between the members of coalitions inside the parliament, are likely to affect policy making.

\section{Part 3 of the book, Parties, Councils, Interest Groups} and Advocacy-Based Policy Analysis, accentuates the existing interactions between politics and policy. The subject of this section is institutional changes favoring increased participation in design and implementation of public policies that have yielded important results in the Brazilian context. 
Côrtes (Chapter 11) analyzes the impacts of councils and neo-corporatist organizations on social assistance policies. The author's detailed qualitative investigation shows the interactions between prominent government actors and social assistance organizations. Overall, tensions and frictions occurred when the federal government decided to increase control over social service delivery to mitigate the hazards of patronage.

Fonseca and Bastos (Chapter 12) bring to readers the successful experience of the HIV/AIDS program in Brazil, analyzing the twofold program objectives of preventing and treating AIDS. In the former, the authors describe multiple stakeholders-government agents, NGOs, and other advocacy groups-involved in a collaborative arrangement aimed to reduce HIV infection in injecting drug users. In the latter, they describe how Brazilian agencies circumvented barriers imposed by major laboratories in order to assure the provision of patented antiretroviral to infected people.

External pressure from media can influence policy making, but how about reforms for improving media regulation? Lattman-Weltman (Chapter 13) examines the limits and perspectives of an independent regulatory body for media and audiovisual production. He argues that the rate of success of a given policy proposal depends more on the characteristics of the proponent than on the project contents.

In turn, Dantas-Neto (Chapter 14) highlights the role of political parties in setting the agenda and influencing amendments on the 1988 constitution. These changes in the rule of law were necessary to implement managerial and institutional reforms. The author shows that parties presenting extensive connections with experienced bureaucrats were more prone to craft successful proposals, thus emphasizing the importance of combining institutional and bureaucratic capabilities in policy making, for ensuring the reforms' viability.

In Chapter 15, Boschi looks at the business associations and their respective role in policy analysis. These organizations cluster manufacturing organizations and aim to protect the interests of their affiliates. In the last decades these business associations have developed capabilities to address relevant policy analysis issues. They also jointly act with public authorities in the delivery of educational services and training in manufacturing-related activities via hybrid organizations (see S-System).

In the last chapter of this section, Góis (Chapter 17) addresses the importance of NGOs in the implementation of pro-diversity policies. The author tells a fascinating story about the interplay between multilateral organizations (such as the World Bank), government bureaucrats, university research groups, organizations fighting against HIV/AIDS, proLGBTT (Lesbian, Gay, Bisexual, Transsexual, and Transgender) activist groups, and organizations fighting racial discrimination. These diverse groups were able to strategize and promote collective action that enabled policies favoring diversity.

Finally, Part 4, Academic and Research Institute-Based Policy Analysis, suggests that expert communities, think tanks, and academic institutions have had a pervasive influence on policy making and policy analysis.

Costa (Chapter 17) provides ultimate evidence on the role that public health experts play in modeling the new unified health system in Brazil (SUS). Despite some implementation problems and fund allocation issues, SUS was able to incorporate into the government's decentralized health system millions of individuals who did not have any access to medical assistance.

In Chapter 18, Teixeira looks at think tanks in Brazil and their influence on policy matters. In contrast to their Anglo-Saxon counterparts, Brazilian think tanks struggle to raise funds from private philanthropy. Despite financial limitations that hamper the influence of these organizations, Teixeira nevertheless presents some examples of effective advice in policy making and policy analysis.

Batista (Chapter 19) and Hollanda and Siqueira (Chapter 20) analyze the role of academic institutions and graduate education in policy analysis, respectively. Batista shows how research centers attached to public and private educational organizations may help to produce knowledge and translate their research finding into policy recommendations in several areas, such as urban planning, income distribution programs, and public security. Hollanda and Siqueira offer an overview of Brazil's Master and Doctoral programs in policy analysis. Coherent with the Brazilian tradition, policy analysis has a multifaceted and polysemic character. An interesting statistic is that public administration/management represents $36.5 \%$ of the public policy courses, followed by economics $(27.3 \%)$, social work $(18.2 \%)$, political science $(10.5 \%)$, and international relations $(7.5 \%)$.

Altogether this book covers a widespread spectrum of themes with contributors from different disciplines. The editors have carefully selected chapter authors who, in turn, have produced a very informative and helpful manuscript. However, despite the fact that in Brazil public administration programs figure as the core area of training in policy analysis, the book does not seem to establish a direct link with the main contemporary theoretical issues in public administration. For example, public service performance (Walker, 
Boyne, and Brewer 2010), goal ambiguity (Chun and Rainey 2005), co-production and innovation in public services (Osborne 2013), and collaborative governance (Agranoff 2012), among others, are not given prominence. Granted, the book is about policy analysis, and thus the dialogue with public administration theories was not central for authors and contributors. Nevertheless, such concepts can be extremely useful to policymakers when designing and analyzing policies, as the prolific production in public administration indicates (some of them published in this journal).

The good news is that these connections exist and the rich content offered in the book can motivate public managers and public administration researchers who read it to build the corresponding bridges. Furthermore, this book can inspire other researchers to produce ancillary materials connecting policy analysis and public administration, not only in the Brazilian context but also in other regions of the world.

\section{References}

Agranoff, Robert. 2012. Collaborating to Manage: A Primer for the Public Sector. Washington, DC: Georgetown University Press.

Ansell, Chris, and Alison Gash. 2008. Collaborative Governance in

Theory and Practice. Journal of Public Administration Research and Theory 18(4): 543-71.

Bovaird, Tony. 2007. Beyond Engagement and Participation: User and Community Coproduction of Public Services. Public Administration Review 67(5): 846-60.

Chun, Young Han, and Hal G. Rainey. 2005. Goal Ambiguity in US Federal Agencies. Journal of Public Administration Research and Theory 15(1): 1-30.

Goffman, Erving. 1963. Stigma: Notes on the Management of Spoiled Identity. New York: Simon and Schuster.

Osborne, Stephen P. 2013. Voluntary Organizations and Innovation in Public Services. New York: Routledge.

Pereira, Carlos, and Bernardo Mueller. 2004. A Theory of Executive Dominance of Congressional Politics: The Committee System in the Brazilian Chamber of Deputies. Journal of Legislative Studies 10(1): 9-49.

Walker, Richard M., George A. Boyne, and Gene A. Brewer. 2010. Public Management and Performance: Research Directions. Cambridge, UK: Cambridge University Press. 